\title{
Immunity Test of Electronic Device for Electrostatic Discharge
}

\author{
Hana Urbancokova*, Jan Valouch and Stanislav Kovar \\ Faculty of Applied Informatics, Tomas Bata University in Zlin,nam. T.G.Masaryka 5555, 76001 Zlin, Czech Republic
}

\begin{abstract}
Due to the increasing susceptibility of electronic device, the importance of electromagnetic immunity to interference also increasing. The basic task of testing the electromagnetic susceptibility of electronic device on the harmful interference is comparison of the data obtained by testing with data which are required by the relevant standards for the device. When the electronic device does not have a sufficient immunity can occur a deterioration of its functionality, temporary failure or even a permanent damage to the device. The aim of this paper is perform the test of electromagnetic susceptibility for the electrostatic discharge at the keyboard of the alarm system. Immunity test will be performed according to instructions in the standards of electromagnetic compatibility.
\end{abstract}

Keywords: Electronic device, Electromagnetic compatibility, Electromagnetic susceptibility, Electrostatic discharge, Immunity test.

\section{Introduction}

Electromagnetic susceptibility (EMS) of the electronic devices to the radiated interference is tested on the basis of the functional criteria. Equipment under test (EUT) is exposed to the influence of interfering emissions whose level is known for us and based on behaviour of the EUT is established a functional criterion. More precisely, it is the monitoring of failure or change in the functionality of the EUT when the device is exposed to the electromagnetic interference. Functional criterion is graded based on the seriousness of the resulting failure as followed:

- Functional criterion A - the EUT must continue in its activities as intended not only during the test but also after the test. Any degradation of performance or loss of function is not allowed as defined in the relevant equipment standard and in the technical specification published by the manufacturer.

- Functional criterion B - the EUT must continue in its activities as intended after the test. Any degradation of performance or loss of function is not allowed, as defined in the relevant equipment standard and in the technical specification published by the manufacturer. During the test, degradation or loss of function or performance is allowed, but change of actual operating state or stored data is not allowed.

- Functional criterion $\mathrm{C}$ - temporary degradation or loss of function or performance is allowed during the test if the function of EUT must be selfrenewable after the test, or it can be restored by the control system or the operator as defined in the relevant equipment standard and in the technical

\footnotetext{
*E-mail address: urbancokova@fai.utb.cz

ISSN: 1791-2377 (C) 2016 Eastern Macedonia and Thrace Institute of Technology.All rights reserved.
}

specification published by the manufacturer.

Often, the literature provides additional functional criterion which expresses an irreversible loss of the functions, or damage or destruction of equipment. [1]

The ideal environment for testing of immunity of electronic devices would be realistic environment in which it will be working. Such environment is changeable and so due to reproducibility of tests we choose the simulated environment for the test which is described in the standards of individual immunity tests. [2]

Important normative documents for our contribution are mainly standards CSN EN 61000-4-2 ed.2. Electromagnetic compatibility (EMC) - Part 4-2: Testing and measurement techniques - Electrostatic discharge - immunity test and CSN EN 50130-4 ed.2 Alarm systems - Part 4: Electromagnetic compatibility - Product family standard: Immunity requirements for components of fire, intruder, hold up, CCTV, access control and social alarm systems. [3]

\section{Electrostatic Discharge}

Electrostatic discharge (ESD) is an interfering signal generated between entities with different electrostatic potential between which the electric charge is transferred, either when approaching or in direct contact of these entities. ESD frequently occurs in the living space such as home or office, or in another environment with low relative air humidity and use of low-conductivity (artificial-fiber) carpets, vinyl garments, etc. During electrostatic pulse can be generated voltage up to $15 \mathrm{kV}$ (or more) and the spectrum of interference has a width up to $1 \mathrm{GHz}$. ESD energy is very small - maximum of $10 \mathrm{~mJ}$.

This type of interference is described in the standard CSN EN 61000-4-2 ed.2 [4]. This standard discusses about the immunity requirements equipment, systems, subsystems and peripherals against electrostatic discharges and testing methods of electromagnetic susceptibility.

There are three kinds of test discharges: 
- contact electrostatic discharge,

- electrostatic discharge an air gap,

- indirect electrostatic discharge on the vertical coupling plane. [1]

The preferred test method is the testing of immunity of the electronic device for contact electrostatic discharge. Tests of immunity on formation of electrostatic discharge an air gap are also performed. Test of immunity of EUT on the last type of ESD (indirect electrostatic discharge on the vertical coupling plane) is only performed when it is determined by the manufacturer or product standard. The basic standard CSN EN 61000-4-2 ed.2 is primarily devoted to the test of immunity of EUT to first two types of ESD.

Test levels and the required test voltage to perform the immunity test on ESD are shown in the following table (Table 1).

Table 1 Test levels and test voltage for immunity test on ESD

\begin{tabular}{c|c|c}
\hline Level & $\begin{array}{c}\text { Contact discharge } \\
\text { Test voltage } \\
\mathbf{k V}\end{array}$ & $\begin{array}{c}\text { Air discharge } \\
\text { Test voltage } \\
\mathbf{k V}\end{array}$ \\
\hline $\mathbf{1}$ & 2 & 2 \\
$\mathbf{2}$ & 4 & 4 \\
$\mathbf{3}$ & 6 & 8 \\
$\mathbf{4}$ & 8 & 15 \\
$\mathbf{X}$ & Special & Special \\
\hline
\end{tabular}

„X" can be any level, above, below or in between the others. The level shall be specified in the dedicated equipment specification. If higher voltages than those shown are specified, special test equipment may be needed.

Internationally standardized series of standards IEC 10004, or CSN EN 61000-4 have described the 5 levels of environments:

- Level 1: well protected environment - normal environment with low levels of interference, in which it can be used also sensitive instruments;

- Level 2: protected environment - environment with a mild levels of interference such as households, shops and offices;

- Level 3: typical industrial environment - demanding environment with a high level of interference;

- Level 4: adverse industrial environment - a special environment with very high levels of interference, such as heavy industry, power plants and distribution systems;

- Level $5(\mathrm{X})$ : Special situations which must be analysed.

\section{ESD Generator and Test Immunity}

The EMS test to electrostatic discharge is performed using the test device called ESD generator, which is shown in Fig.1. The end part of ESD generator usually takes the form "pistol" with interchangeable tips of the discharge electrode. Both interchangeable tips can see in the Fig.1 and their illustration is closer on Fig.2. ESD generator is most connected with a source of high voltage to a one cable and the other one is connected to the ground reference plane. A simplified diagram of the ESD generator is shown in Fig. 3.

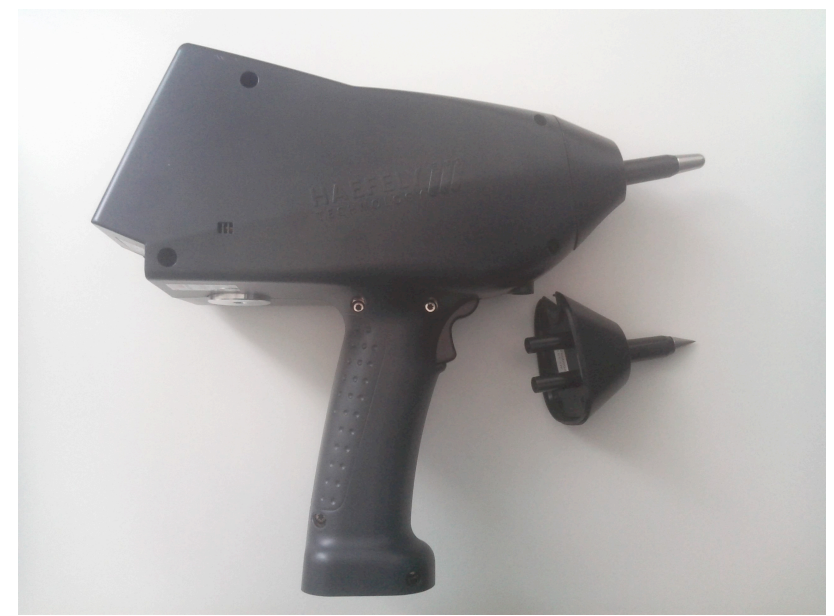

Fig. 1 ESD generator (simulator of electrostatic discharges)

ESD generator from the company Haefely Technology has a touchscreen on which can be set the type of discharge tip (tip for contact electrostatic discharge or tip for electrostatic discharge an air gap), the number of discharges (number of repetitions discharge) and the size of voltage given to each discharge.

a)

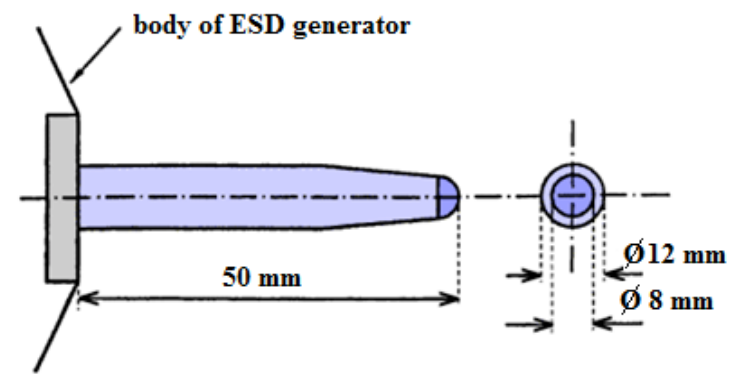

b)

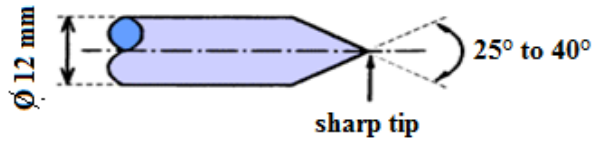

Fig. 2 Interchangeable tips of ESD generator [1], a) tip for air discharge, b) tip for contact discharge

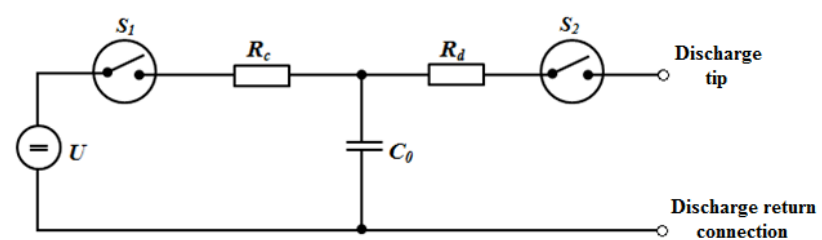

Fig. 3 A simplified diagram of the ESD generator

The main parts of the ESD generator:

- $\quad$ power supply unit $(U)$,

- charging resistor $\left(R_{c}\right)$,

- capacitor accumulating and distributing energy $\left(C_{0}\right)$,

- discharge resistor $\left(R_{d}\right)$

- voltage indicator,

- charge switch $\left(S_{1}\right)$,

- discharge switch $\left(S_{2}\right)$,

- interchangeable tips of the discharge electrode,

- discharge return cable. [4] 
A typical value of the capacitor $C_{0}$ is $150 \mathrm{pF}$ and a value of the discharge resistor $R_{d}$ is $330 \Omega$ based on the standards.

Test of immunity to the electrostatic discharge an air gap is done through the ESD generator, that approaching to the equipment under test with its tip and the generator switch is closed. The tip of ESD generator is approaching to the EUT until the breakdown voltage falls below voltage of charged capacitor $C_{0}$. Charged capacitor is discharged when the spark jumps into EUT. Each single discharge is repeatedly applied at least 10 times on the chosen the place of EUT. Electrostatic discharges are in a polarity to which the device is most sensitive.

Test of immunity to the contact electrostatic discharge is done through the ESD generator whose tip is constantly connected with the EUT on the chosen the place. The switch of ESD generator will be closed and capacitor $C_{0}$ will be discharged. Between the EUT and the tip of generator will occur to discharge. This type of discharge is also applied for EUT at least 10 times with breaks between discharges at least $1 \mathrm{~s}$. The impulse of output current of ESD generator at a contact discharge is shown in Fig.4.

Both types of immunity tests for electrostatic discharge are carried out on place and on the surface of the EUT that are accessible by the operator devices under normal use. Among such places we include for example control panels, keypads, switches, buttons and other controls access but also the places like metal part of the casing device (isolated from ground), the indicators, light-emitting diodes, various grids, connector covers and etc. [5] [6] [7]

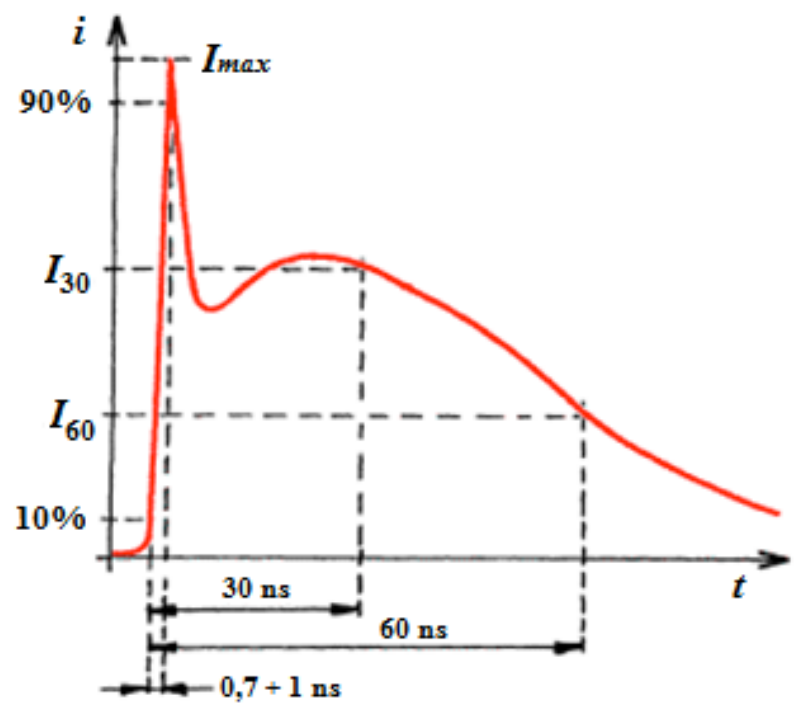

Fig. 4 The impulse of output current of ESD generator at a contact discharge [1]

\section{Immunity Test to Electrostatic Discharge}

On the testing of electronic device, which is keyboard JA$81 \mathrm{E}$ from the system Oasis, we performed the test according to standard CSN EN 50130-4 ed. 2 [8]. In this standard the requirements for immunity test are described more closely. According to the standard the immunity test of EUT is performed by the action of electrostatic discharge on the part of the equipment which are accessible to the operator. The test is also performed of electrostatic discharge on the vertical coupling plane at a distance of $0.1 \mathrm{~m}$ from the EUT. The basic realization of workplace and the test is described in standard CSN EN 61000-4-2 ed.2 [4].
For testing of electrostatic discharge are intended levels of discharges in the standard CSN EN 50130-4 ed. 2 in the following manner:

- air electrostatic discharge $-2 \mathrm{kV}, 4 \mathrm{kV}$ a $8 \mathrm{kV}$,

- contact electrostatic discharge $-6 \mathrm{kV}$.

For all devices covered by the standard CSN EN 501304 ed. 2 is intended functional criterion A for testing electrostatic discharge. This is the criterion according to which the device must operate continuously as intended after the test. It must not experience any damage, malfunction or change of status of the EUT during testing. Only the flashing indicator was permissible if it does not occur any residual change in the EUT or any change in output which a connected device could be interpreted as a change. [9]

The keyboard has been connected to the control panel JA 82-K. The PIR (passive infra-red) motion detector JS-20 and the siren SA-913TM were subsequently connected to the control panel. These components are placed on the insulating washer and at a distance of $0.5 \mathrm{~m}$ from the keyboard in the test (see Fig. 5).

We placed the entire assembly on a wooden table $80 \mathrm{~cm}$ high, with the upper surface of 160x $80 \mathrm{~cm}$. Table was placed on the ground reference plane and on the entire surface of the table was also placed ground reference plane. E EUT and all cables connected with the EUT were placed as described in the standard CSN EN 61000-4-2 ed. 2. ESD generator was powered from a source (a charging source, which is part of the ESD generator). The generator was properly grounded according to the manufacturer's instructions. The parameters of the ESD generator from Haefely EMC Technology satisfy the requirements arising from the provision set of standards CSN EN 55016 Specification for radio disturbance and immunity measuring apparatus and methods.

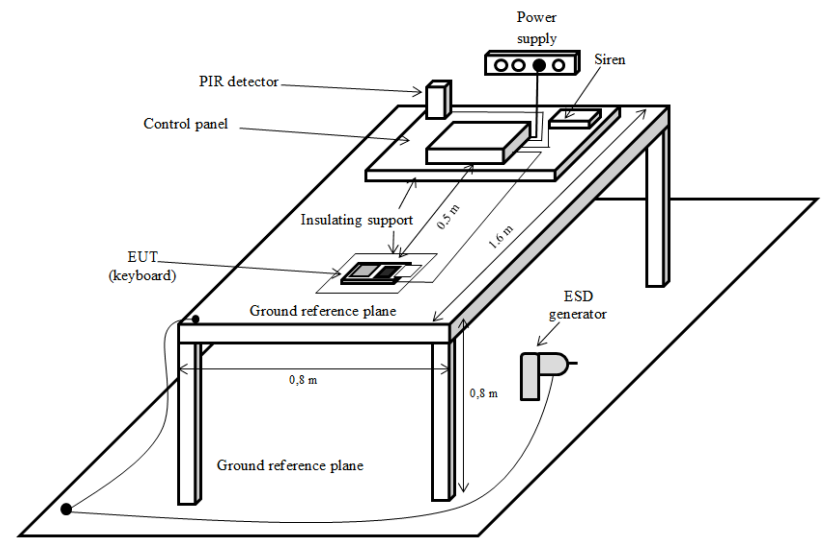

Fig. 5 Workplace for testing ESD

At the beginning of the testing was on the EUT performed functional test. We have chosen that the entire assembly have been brought into the security surveillance mode (ON state) based on the assumption that the system is most sensitive in this state. Any changes in the operating of keyboard state would be acoustically reported by keyboard or siren.

As the first test the electrostatic discharge was performed (air discharge and contact discharge) on the vertical coupling plane near the EUT. No changes on the EUT were observed in this type of immunity test for all of tested voltages.

Another discharges applied to the EUT were electrostatic discharges an air gap. Discharge from ESD generator to the EUT has not been observed at a voltage of $2 \mathrm{kV}$ and the 4 $\mathrm{kV}$ (both polarities). The results of the tests we have 
ascribed to the fact that the whole surface of the keyboard is made of non-conductive material and the applied voltage is not sufficient for the formation of discharge between the generator and inner parts of the EUT. At the voltage $8 \mathrm{kV}$ (both polarities) we observed the occurrence of discharge at the site of point, which detects whether cover of buttons is closed or not (see Fig.6). Formation of these discharges has been very difficult because this point was necessary to press so that was formed a greater space in the plastic cover. About same result we tried also for other keys on the keyboard, but we have not recorded formation of discharge in these places. Although the discharge was created between the ESD generator and the EUT we have not recorded any change in the keyboard.

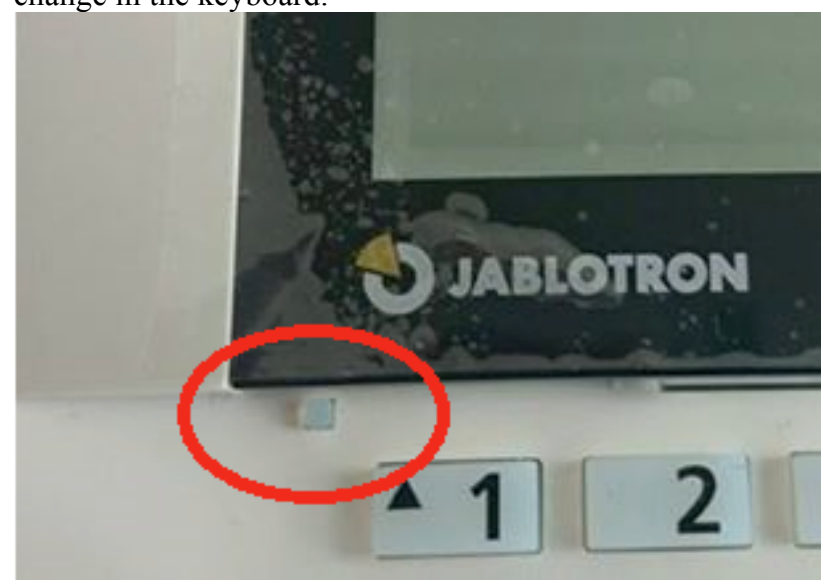

Fig. 6 Point for detecting whether the cover is closed

The last type of immunity test for electrostatic discharge is test for contact discharge with voltage $6 \mathrm{kV}$. In this test, we found that the electrostatic discharge occurs at the bottom of the display of keyboard at the place where the display is connected to the cover of keyboard. The application of contact electrostatic discharges was realized at the place that we see in Fig. 7.

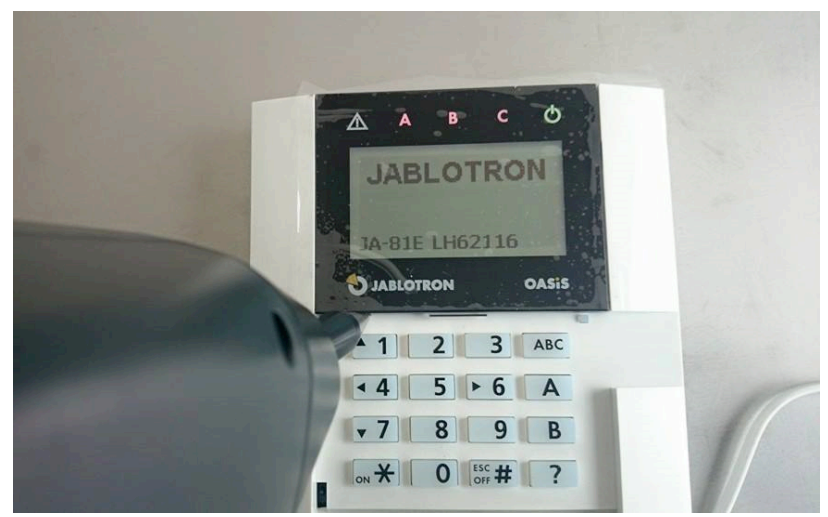

Fig. 7 The application of contact electrostatic discharges

The occurrence of discharges was the most frequently in this place. We have applied 10 discharges with a voltage of $+6 \mathrm{kV}$ and we have seen 4 times the change on the display. Clusters of points have been accidentally switched on the edge of information display. This state is repeated at discharges 1 to 6 and 8 to 10 at the voltage $-6 \mathrm{kV}$. The display was erased after application of the seventh discharge. When the display was turned on again instead of the original text (JA-81E LH62116) was only shown the letter (Fig.8). This situation lasted until the end of the test.

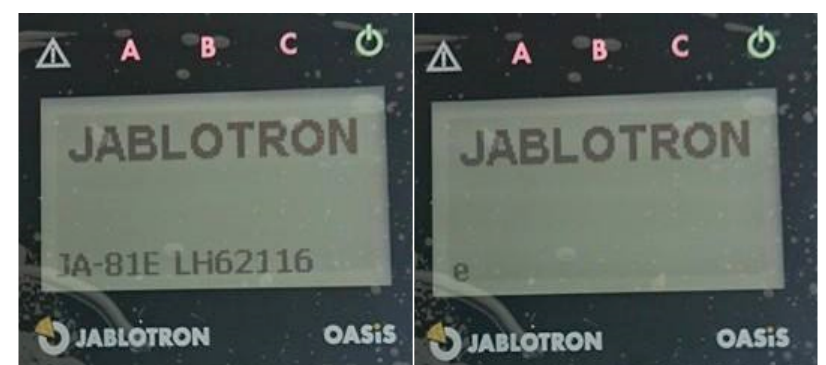

Fig. 8 Change in the display

After the test we performed a functional test of the EUT. The keyboard did not show the problem with functions such as entry of codes and control of the entire assembly. The upper bar with indicators (indicator of turn on the system, status of subsystems $\mathrm{A}, \mathrm{B}$ and $\mathrm{C}$ and warning indicator) worked also properly. Error on the keyboard was created only the display. Random of clusters of points have been displayed on the display instead of the text about the event (Fig. 9). This state has not changed even when the keyboard was turned off and then turned on again. Change did not occur even after the restarts of control panel.

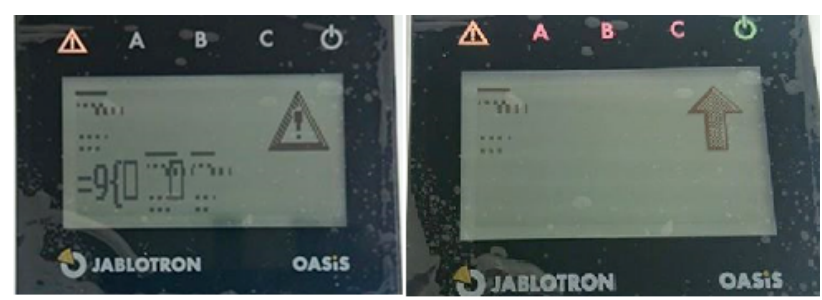

Fig. 9 Random of clusters of points on the display

\section{Conclusion}

Today the electronic devices cannot be sold on the European market if they do not have the mark of conformity showing that the device complies of the requirements of the EMC Directive. Therefore, it is necessary that each device has been tested according to the standards of electromagnetic compatibility prior to marketing. The tests are performed not only to detect levels of electromagnetic interference, which device produces, but also to determine its immunity to interference, which the device could be exposed to under normal use. [10] [11]

One of such tests is to test of devices for the electrostatic discharge according to standard CSN EN 61000-4-2 ed.2. Device tested according this standard has been the keyboard JA-81E from the system Oasis, whose its entire outer structure including the buttons and the display, is made of non-conductive material.

Based on the testing it was found that the electrostatic discharges may occur in certain places on this keyboard and with sufficiently high test voltage. Since that we had available only one keyboard of this type, we cannot certainly say whether the same electrostatic discharges (with the same effect) would have been created on all keyboards of this type. However may be it was the faulty product in our case. Discharges were created in a few places and when we applied a whole series of discharges in one place, we have caused damage to the keyboard. This damage causes the wrong instructions on the display of keyboard and subsequently it will be examined. Based on the extent of the damage the repair option will be determined. 


\section{Acknowledgment}

This work was supported by the Ministry of Education, Youth and Sports of the Czech Republic within the National Sustainability Programme project No. LO1303 (MSMT-
7778/2014) and also by the European Regional Development Fund under the project CEBIA-Tech No. CZ.1.05/2.1.00/03.0089 and Internal Grant Agency of Tomas Bata University under the project No. IGA/CebiaTech/2016/005

\section{References}

1. SVACINA, J.: Electromagnetic compatibility: Principles and comment. University of Technology, Brno (2001), p. 156. ISBN 80-214-1873-7.

2. CLAYTON R., P.: Introduction to electromagnetic compatibility. 2nd ed. Hoboken: Wiley-Interscience (2006), XXI, 983 p. ISBN 9780471755005.

3. VALOUCH, J.: Electromagnetic Compatibility of Alarm Systems Legislative and Technical Requirements. In: Security Magazin. Issue No 106, 2/2012. Praha: Security Media (2012). ISSN 12108273. p. $32-36$

4. CSN EN 61000-4-2 ed.2: Electromagnetic compatibility (EMC) Part 4-2: Testing and measurement techniques - Electrostatic discharge immunity test. The Czech Office for Standards, Metrology and Testing, Prague (2009).

5. BIENKOWSKI, P., TRZASKA, H.: Electromagnetic measurements in the near field. Raleigh, NC: SciTech Pub. (2012), 217 p. ISBN 9781613531068.

6. OTT, H. W.: Electromagnetic compatibility engineering. USA, Hoboken, N.J.: John Wiley \& Sons (2009), XXV, 843 p. ISBN 0470189304.

7. NEACSU, Oana-Maria, Marius Valerian PAULET and Alexandru SALCEANU. Analysis of current pulse generated by electrostatic discharge simulator. In: 2014 International Conference and Exposition on Electrical and Power Engineering (EPE). IEEE (2014), p. 484-487. DOI: 10.1109/ICEPE.2014.6969955. ISBN 978-1-4799-5849-8.

8. CSN EN 50130-4 ed. 2: Alarm system. Part 4: Electromagnetic compatibility - Product family standard: Immunity requirements for components of fire, intruder, hold up, CCTV, access control and social alarm systems. The Czech Office for Standards, Metrology and Testing, Prague (2012).

9. VACULIK, E., VACULIKOVA, P.: Electromagnetic compatibility of electrotechnical systems: A practical guide to technology limitations HF electromagnetic interference. 1. ed. Grada Publishing, Prague (1998), p. 487. ISBN 80-716-9568-8.

10. VALOUCH, J.: Technical requirements for Electromagnetic Compatibility of Alarm Systems. In: International Journal of Circuits, Systems and Signal Processing. Volume 9. USA, Oregon: North Atlantic University Union (2015). p. 186 - 191. ISSN: 1998-4464. p. 6.

11. VALOUCH, J.: Requirements for Alarm Systems in Terms of the Electromagnetic Compatibility. In: KRIVANEK, V. and STEFEK, A. (ed.) International Conference in Military Technology Proceeding, ICMT'13, Brno: University of Defence (2013), p. 589 - 596. ISBN 978-80-7231-918-6. 